\title{
Role of Diffusion Weighted Imaging in the Differentiation between Benign and Malignant Breast Masses in Correlation with Sono-Mammography
}

\author{
DALIA M. BAYOUMI, M.D.*; EMAN ABD EL-SALAM, M.D.*; MARWA SHABANA, M.Sc.*; \\ OMAR FAROUK, M.D.** and NERMIN SOLIMAN, M.D.* \\ The Departments of Radiology* and Clinical Oncology**, Faculty of Medicine, Mansoura University, Mansoura, Egypt
}

\begin{abstract}
Background: Evaluation of the role of DWI in differentiation between benign and malignant breast lesions with Sono-mammographic and pathologic correlation.
\end{abstract}

Aim of Study: To evaluate the role of diffusion weighted imaging in the differentiation between benign and malignant breast lesions with sono-mammographic and histopathologic correlation.

Material and Methods: This study included 30 females (with 31 breast lesions). Their ages ranged from 21 to 65 years. They were subjected to history, Clinical examination, sono-mammography, MRI and histopathology. The Sonomammographic categories included were 3,4 and 5. We used 1.5 T MRI system and the sequences performed included T1 $\mathrm{W}, \mathrm{T} 2 \mathrm{~W}$ and STIR. The DWI was done using $b$-values 0 , $500,1000 \mathrm{~s} / \mathrm{mm} 2$ then the ADC values were calculated. For statistical analysis we used $t$-test and ROC curve.

Results: The mean age was 42.6 years. The most common clinical presentation was palpable breast lump (16 patients). We had BIRADS 3 (6 lesions), BIRADS 4 (17 lesions), BIRADS 5 (8 lesions). By histopathologic examination we had 9 benign neoplasm, 10 malignant neoplasm, 5 post conservative changes, 3 fibrocystic changes, 1 granulomatous mastitis, 2 inflammatory hyperplastic changes \& 1 localized adenosis. The mean ADC for benign lesions was $1.42 \times 10^{-3}$ $\mathrm{mm} 2$ and for malignant lesions was $0.88 \times 10^{-3} \mathrm{~mm} 2$. The cut off value between malignant lesions and benign lesions was $\leq 1.175$. Finally there was weak negative statistical correlation between sono-mammographic BIRADS results and the ADC values.

Conclusion: The DWI and ADC values are useful tools for the differentiation between benign and malignant breast lesions especially in patients with contrast intolerance. These techniques showed considerable specificity and positive predictive values when compared to Sono-mammographic BIRADS and histo-pathologic results.

Key Words: DWI - Benign - Malignant-Breast masses Sono-mammography.

Correspondence to: Dr. Dalia M. Bayoumi, E-Mail: daliabayoumi1982@yahoo.com.

\section{Introduction}

IMAGING of the breast is a vital procedure, not only for breast cancer screening but also for diagnosis, evaluation, treatment and follow-up of any breast lesion [1].

The basic digital Mammography is the main investigation for imaging of the breast lesions especially in the women with dense breasts, but mammographic images alone are usually not enough to determine the existence of benign or malignant disease and the radiologist in some circumstances recommend further diagnostic studies [2]

Ultrasonography is the perfect complementary to the mammography since both of the modalities are easily available and relatively less time consuming. Ultrasonography and mammography cannot replace each other but to suggest single modality, ultrasonography is better in younger population and BIRADS $1,2 \& 3$ lesions. Whereas, mammography is better in older population and in BIRAD $4 \& 5[3]$

Magnetic resonance imaging (MRI) is gaining wide spread acceptance as an essential tool for examination of breast pathology. In comparison with ultrasound and mammography, it has high sensitivity due to the use of contrast enhancement material (1); (2) ; (3). Dynamic contrast enhanced magnetic resonance imaging (DCE-MR) was found to have high sensitivity (>90\%) and moderate specificity $(85 \%)$ as demonstrated by multi-centre trials (4); (5); however, there is confounding overlap between benign and malignant lesions on some occasions, making the distinction a rather difficult task on the basis of conventional MRI features [4] 
Diffusion-weighted imaging (DWI) is an advanced MRI technique that derives its image contrast from variation of water molecules motion in tissues (Brownian motion) which in fact is closely related to the tumour cellularity and integ-rity of cell membranes. Both qualitative and quant-itative assessment can be made, and the latter is achieved through measuring the apparent diffusion coefficient (ADC), that is directly proportional to the water diffusion in the tissue [1]

\section{Patients and Methods}

This study included 30 female patients. Their ages ranged from 21 to 65 years old. It was conducted at the Radiology Department of Mansoura University Hospital over the period from February 2014 to December 2016.

They were referred from Mansoura University Hospital \& Oncology Centre, Mansoura University.

The study was approved by our institution's ethics committee, and all patients gave their informed consent before inclusion in the study.

\section{Inclusion criteria:}

- Patients suspected to have breast lesion on clinical bases.

- Patients subjected to sono-mammogram and revealed breast lesions of BIRADS 3, 4, 5.

- Patients who had past history of operated malignant breast lesions and came now suspected to have local regional recurrence.

\section{Exclusion criteria:}

- Patients who have contraindications to do MRI; as patient with cardiac pace maker, patients with cochlear implant \& ocular foreign body and claustrophobia.

- Pregnant female not candidate for Mammography.

\section{All the patients were subjected to the following:}

I- Full history (that was taken by our colleagues at both Oncology Center and radiology departments).

II- Clinical examination (by the referring physician).

III- Radiological investigations which are: 1- Mammography.

2- Ultrasound: Was done to all patients.

3- MRI examination: The MRI examinations were done before breast biopsy.
IV- Histo-pathology which is the standard reference of our results.

\section{A- Mammography:}

Cranio caudal (CC) and medio lateral (ML) views were done for all patients above 30 years old $(\mathrm{N}=26)$, then these views analysed regarding the; Breast composition, masses, calcifications, architectural distortion, asymmetries, intra-mammary lymph nodes, skin lesion, ductal dilatation, and finally associated features (skin retraction, nipple retraction, skin thickening, trabecular thickening, axillary lymph adenopathy, calcifications, as well as location of the lesion (laterality, quadrant, depth, distance from nipple).

\section{B- Ultrasound:}

Breast ultrasound was done for all patients using high frequency probe $(12-15 \mathrm{MHz})$ and we comment upon; tissue composition, masses (shape, orientation, margin, echopattern, posterior features), calcification (in mass, outside mass, Intra-ductal), and associated features (architectural distortion, duct changes, edema and intra lesional vascularity).

Classification of breast lesions was based on the Breast Imaging Reporting and Data System (BIRADS). The following Sono-mammographic BIRADS categories were selected for breast MRI study:

- Category 3: Probably benign finding.

- Category 4: Possibly benign finding.

- Category 5: Highly suggestive of malignancy.

\section{C- MRI examination:}

Bilateral breast examination was done for patients using 1.5 T system (Philips Ingenia, Best, Netherland). Patients laid prone using bilateral single breast coil. The conventional MRI sequences performed included T1 W sequence (TR $512 \mathrm{~ms}$, TE $8 \mathrm{~m}$ ) axial section, T2 W sequence (TR 2000ms, TE $8 \mathrm{~ms}$ ) axial section, STIR [TR 4000ms, TE 70 $\mathrm{ms} \&$ inversion time (TI) was $175 \mathrm{~ms}]$ and five continuous dynamic contrast-enhanced acquisitions in axial sections were performed using a bolus of gadopentatedimeglumine, in a dose of $0.2 \mathrm{mmol} / \mathrm{kg}$ that injected using an automated injector at a rate of 3-5 $\mathrm{ml} / \mathrm{sec}$ through an 18-20 gauge intravenous cannula inserted in an antecubital vein. This was followed by a bolus injection of saline (total of $20 \mathrm{ml}$ at $3-5 \mathrm{ml} / \mathrm{sec}$ ) dynamic studies were made in the axial plane with using a FLASH 3D GRE$\mathrm{T} 1 \mathrm{~W} 1$ with the following parameters: TR 3-4 ms, TE $1.5 \mathrm{~ms}$, flip angle 10 degrees, slice thickness $2 \mathrm{~mm}$ with no inter-slice gap, field of view (FOV) $450 \mathrm{~mm}$ and the matrix was $256 \times 256$. All the dif- 
fusion weighted images were obtained by echoplanar imaging (EPI) sequence with single shot at $b$ value $b$-values $0,500,1000 \mathrm{~s} / \mathrm{mm}^{2}$ using at least two $b$-values the $b 0 \mathrm{~s} / \mathrm{mm}^{2}$ with other $b$-values, in patients with fibrocystic changes we use $b$-value of $15000 \mathrm{~s} / \mathrm{mm}^{2}$ as the difference between the signal intensity of lesions and that of normal breast parenchyma is more evident, TR/TE: 1800/75, FOV: $350 \mathrm{~mm}$, and slice thickness: $3 \mathrm{~mm}$, echo-train length: 1800/93.8, bandwidth: 1, matrix size: 25 $\mathrm{MHz}$, number of signals averaged: $360 \mathrm{~mm}$, number of slices: 16 , slice thickness: $10 \mathrm{~mm}$, intersection gap: 5mm, Total scan duration: 3: 44 minutes. The images were transferred to a workstation for processing.

The ADC values were calculated automatically by placing the region of interest (ROI) within the confines of the lesions. The reference image was obtained from the contrast-enhanced images as the latter had better resolution. The enhanced part of the lesion was selected for evaluation on the corresponding DW-MRI. The scanner software provides the mean value within the ROI, which equals the ADC value (multiplied by $10^{-3}$ ). The area of the ROI ranged from $4-10 \mathrm{~mm}^{2} \mathrm{~mm}$. Apparent necrotic or cystic components were avoided by referring to conventional MR images.

\section{Statistical analysis:}

$t$-test statistical study was used for statistical analysis of the data comparing the mean ADC values and $\mathrm{ADC}$ ratio between benign and malignant breast masses with reference to the Histopathological or follow-up data. A $p$-value $<0.05$ was considered significant. Receiver operating characteristic (ROC) curve statistical study used for presentation of data and the optimal cut-off levels for differentiating benign versus malignant lesions were determined by identifying the points where the sensitivity and specificity were equal on the ROC curves. According to ROC analyses, the sensitivities and specificities of ADC value and ADC ratio were obtained.

\section{Results}

A total number of 30 patients were enrolled in this study, and the age range was 21 to 65 years old with mean age was 42.6 years old. Our patients had different clinical presentation including; 16 patients presented by palpable breast lump, 3 patients presented by inflammatory manifestations, 2 patients presented by palpable lump in the axillary region, 2 patients presented with nipple discharge, 5 patients came for postoperative follow-up and 2 patients came for screening mammography (we had more than one clinical presentation in the same patient). One of our patients had two different lesions in the same breast, so we had 31 one lesion in this study.

Different mammographic \& sonographic findings were seen in our patients (Tables 1,2), and according to these findings the patients were categorized according to Breast imaging reporting and data system (BIRADS) into BIRADS 3 (no.6 cases), BIRADS 4 (no. 17 cases), BIRADS 5 (no. 8 cases). (Table 3 ).

Table (1): Mammographic findings in our 30 patients (with 31 lesions).

\begin{tabular}{lc}
\hline Mammographic Findings & Number \\
\hline Mass & 12 \\
Calcification & 1 \\
Asymmetries & 3 \\
Architectural distortion & 4 \\
Intra-mammary LNs. & 1 \\
Skin lesion & 0 \\
Dilated duct & 3 \\
Associated features: & \\
Skin retraction & 1 \\
Nipple retraction & 1 \\
Skin thickening & 6 \\
Trabecular thickening & 2 \\
Axillary adenopathy & 4 \\
Calcification & 3 \\
\hline
\end{tabular}

$N . B .: *$ We had seen more than one finding in the one patient.

Table (2): Ultra-sonographic findings in our 30 patients.

\begin{tabular}{ll}
\hline Ultra-sonographic findings & Patients number \\
\hline Mass: & 15 \\
Solid & 3 \\
Cystic & 1 \\
Complex & 3 \\
Calcification (inside mass) & 4 \\
Focal distortion & 4 \\
Dilated ducts & 4 \\
Skin Thickness, edema & 7 \\
Lymph node &
\end{tabular}

Table (3): Sono-mammographic BIRADS in the patients.

\begin{tabular}{ll}
\hline $\begin{array}{l}\text { BIRADS category/assessment/ } \\
\text { clinical management }\end{array}$ & Patient number \\
\hline $\begin{array}{l}\text { BIRADS 3/(probably benign findings)/ } \\
\text { (short interval follow-up) }\end{array}$ & 6 \\
$\begin{array}{l}\text { BIRADS 4/(possibly benign findings)/ } \\
\text { (biopsy should be considered) }\end{array}$ \\
$\begin{array}{l}\text { BIRADS 5/(highly suggestive of malignancy)/ } \\
\text { (biopsy should be considered) }\end{array}$ \\
$\begin{array}{l}\text { N.B.: We had three patients with fibrocystic changes. Complicated } \\
\text { cysts are seen in all of them, for that we categorized them as } \\
\text { BIRADS } 3 .\end{array}$
\end{tabular}


Different pathologies were present among our patients on histopathologic study including; 9 benign neoplasm, 10 malignant neoplasm, 5 post conservative therapy changes, 3 fibrocystic changes, 1 granulomatous mastitis, 2 inflammatory hyperplastic changes without atypia \& 1 localized adenosis as shown in (Tables 4,5).

Table (4): Histopathologic analysis of the 31 breast lesions.

\begin{tabular}{lc}
\hline Histopathologic analysis & $\begin{array}{c}\text { Number of } \\
\text { lesions }\end{array}$ \\
\hline Benign neoplasm & 9 \\
Malignant neoplasm & 10 \\
Post-operative changes: & \\
$\quad$ Seroma & 2 \\
$\quad$ Recurrence & 1 \\
$\quad$ Fibrosis & 2 \\
Fibrocystic changes with complicated cysts & 3 \\
Granulomatous mastitis \& chronic abscess & 1 \\
Inflammatory hyperplastic changes without atypia & 2 \\
Localized fibroadenosis & 1 \\
\hline Total & 31 \\
\hline
\end{tabular}

Table (5): BIRADS results in association with histopathologic results.

\begin{tabular}{llll}
\hline BIRADS category & \multicolumn{2}{c}{ Pathology } & \multirow{2}{c}{$\begin{array}{c}\text { Chi-Square } \\
\text { test }\end{array}$} \\
\cline { 2 - 3 } & Benign & Malignant & \\
\hline $\begin{array}{l}\text { BIRADS 3 } \\
\text { category }(\mathrm{N}=6)\end{array}$ & $6(35.3 \%)$ & $0(0.0)$ & \\
$\begin{array}{l}\text { BIRADS } 4 \\
\text { category }(\mathrm{N}=17)\end{array}$ & $14(64.7 \%)$ & $3(27.3 \%)$ & $\chi^{2}=18.12$ \\
$\begin{array}{l}\text { BIRADS 5 } \\
\text { category }(\mathrm{N}=8)\end{array}$ & $0(0.0)$ & $8(72.7 \%)$ & $p<0.001$ \\
\hline
\end{tabular}

DWI was done for all our patients and we detected the following findings; mass lesion $(n o=21) \&$ non mass lesions $(n o=10)$. For the mass lesions, segmental distribution was found in 5 cases $\&$ non segmental distribution in 5 cases. Also the diffusion criteria (regarding the restricted or free diffusion) were assessed for the mass and nonmass lesions in relation to the histopathological findings as shown in (Tables 6,7).
Table (6): Characters of 21 mass lesions on DW images in relation to the histopathology.

\begin{tabular}{lccc}
\hline Diffusion & Benign & Malignant & Total \\
\hline Restricted & 0 & 7 & 7 \\
Free & 14 & 0 & 14 \\
\hline Total & 14 & 7 & 21 \\
\hline
\end{tabular}

Table (7): Characters of 10 non-mass lesions on DW images in relation to the histopathology.

\begin{tabular}{lccc}
\hline Diffusion & Benign & Malignant & Total \\
\hline Restricted & 2 & 4 & 6 \\
Free & 4 & 0 & 4 \\
\hline Total & 6 & 4 & 10 \\
\hline
\end{tabular}

The ADC values were automatically calculated by placing the ROI well within the lesion. Apparent necrotic or cystic components were avoided by referring to conventional MR images. The mean ADC for benign lesions was $1.42 \times 10^{-3} \mathrm{~mm}^{2} / \mathrm{sec}$ \pm 0.44 and for malignant lesions was $0.88 \times 10^{-3}$ $\mathrm{mm} / \mathrm{sec} \pm 0.17$. The cut off value of the mean ADC to differentiate between malignant lesions and benign lesions was $\leq 1.175$ with the calculated $p$-value was $<0.001$. While the Sensitivity, Specificity, Positive predictive value, Negative predictive value and Accuracy were $0.001,100 \%, 88.2 \%$ $84.6 \%, 100.0 \% \& 92.86 \%$ respectively and finally the ROC curve analysis was done as shown in (Fig. 1).

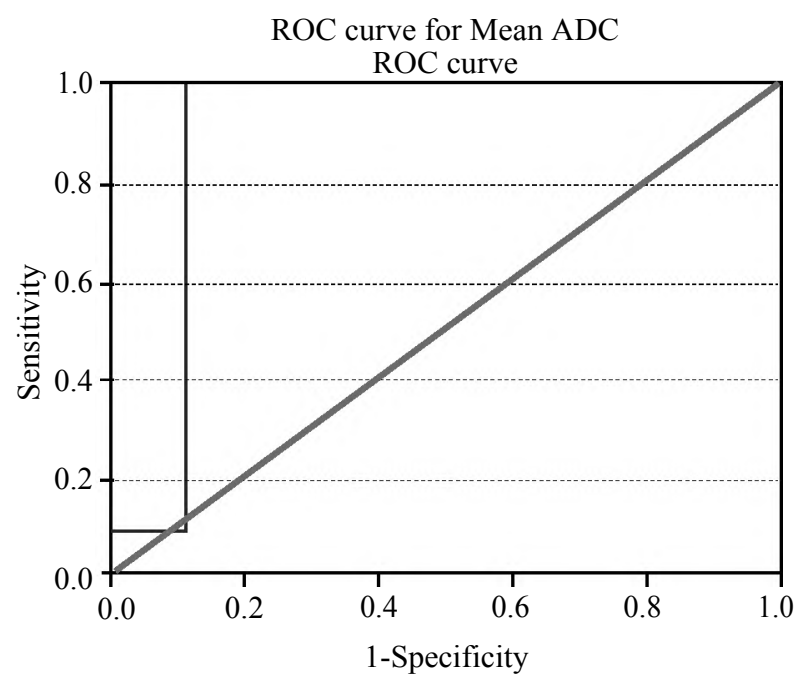

Fig. (1): ROC curve for the mean ADC value. 
Case (1)
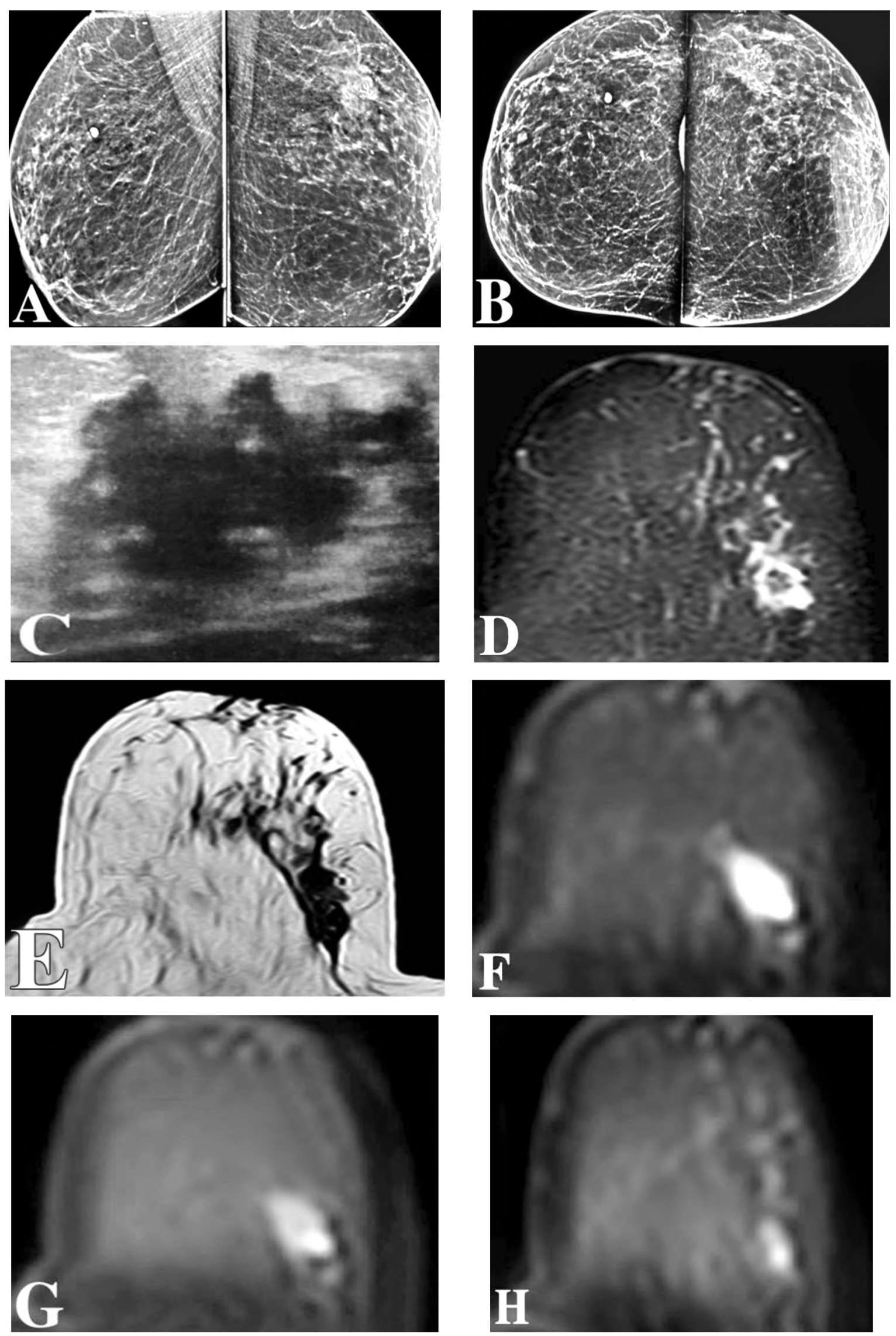


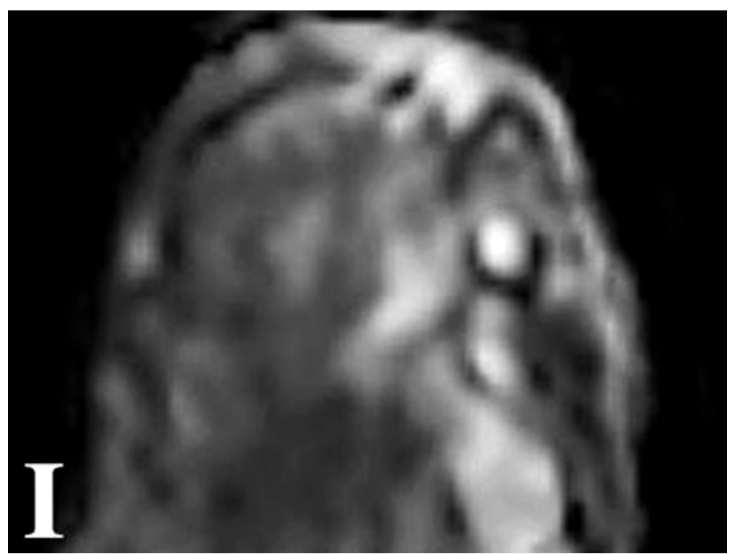

Case (1): Pathologically proven grade II invasive ductal carcinoma. Figs. (A) and (B): Medio-lateral oblique and cranio-caudal mammographic views showing mass density in the left upper outer quadrant. Fig. (C): Ultrasound shows a speculated mass corresponding to the mammographic density. Fig. (D): STIR image showing high SI of the mass. Figure E: T2WI image showing low SI of the mass. Figs. (F, G) and $(\mathrm{H})$ show the diffusion restriction at different $b$-values. Fig. (I), the ADC map confirms the restricted diffusion within the mass and the ADC value measured was: $0.85 \times 10^{-3} \mathrm{~mm}^{2} / \mathrm{s}$.

\section{Case (2)}

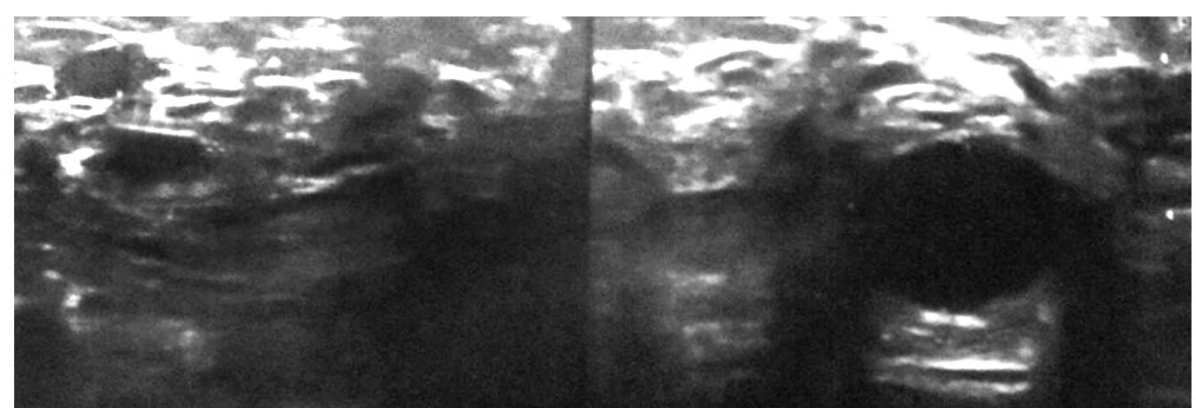

A
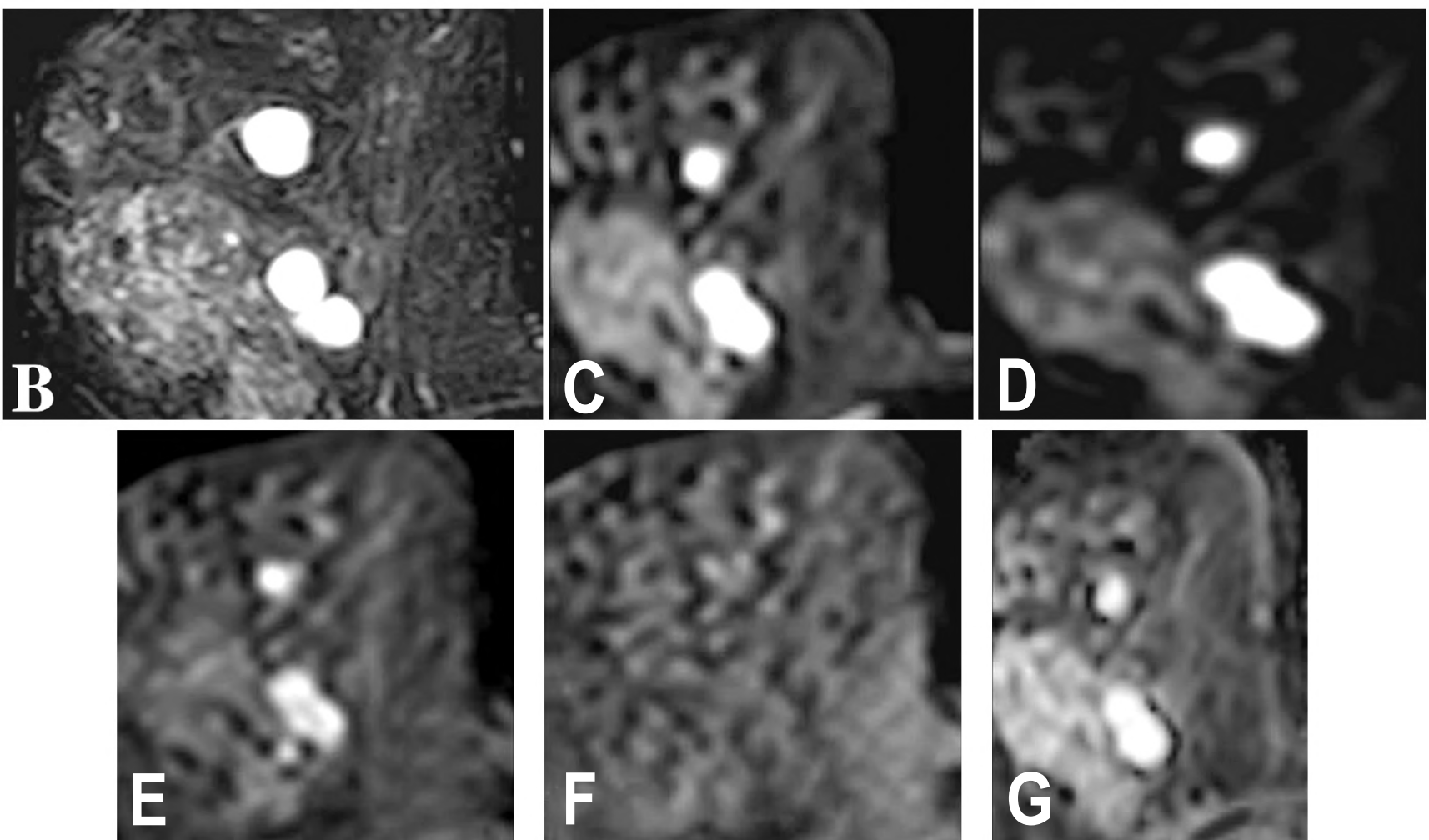

Case (2): Pathologically proven fibrocystic changes in a patient with strong positive family history of breast cancer. Fig. (A): Ultrasound images showing multiple breast cysts. Fig. (B): STIR image showing the high SI of the cysts. Figs. (C, $\mathrm{D}, \mathrm{E}$ and $\mathrm{F}$ ): Show the facilitated diffusion at different $b$ - values. Fig. (G), the ADC map confirms the facilitated diffusion and the ADC value measured (within the largest cyst) was: $2.3 \times 10^{-3} \mathrm{~mm} 2 / \mathrm{s}$. 


\section{Discussion}

Magnetic Resonance Imaging (MRI) is used in breast imaging to improve the detection and characterization of multiple, small or non-palpable breast lesions. Diffusion weighted imaging (DWI) is the only non-invasive MRI technique used for detecting the Brownian motion of water molecules in vivo. It quantifies the limitation of Brownian motion on those molecules through apparent diffusion coefficient (ADC) values. The correlation between the ADC value and the cellular density has been verified. The higher the cellular density as in malignant tumours, the lower the ADC value in DWI, while the lower the cellular density as in benign lesions, the higher the ADC value in DWI [3].

Diffusion weighted imaging (DWI) is currently used in breast MRI examination and has good diagnostic performance in the detection of breast lesions and the differentiation between benign and malignant tumours even in the dense fibroglandular breast parenchyma. Diffusion weighted imaging (DWI) could be a promising tool in screening for breast cancer without using contrast medium, especially for patients with renal dysfunction or previous reactions to contrast agents and will relieve the cost of examination [6].

Our study was conducted in Radiology Department of Mansoura University Hospital during the period from February 2014 to December 2016. The patients were referred to us from Mansoura university hospital \& oncology center-Mansoura University. The study was approved by our institution's ethics committee, and all patients gave their informed consent before inclusion in the study.

All the patients have been examined with sonomammography \& un enhanced MRI technique using 1.5 T system (Philips Ingenia, Best, Netherland) using STIR sequence, T2 Weighted Imaging, Diffusion Weighted Imaging (DWI), followed by measurement of ADC with in the selected area of interest.

This study included 30 patients with 31 breast lesions to evaluate the role of DWI and ADC in the probably of benign and suspicious breast lesions after mammographic and ultra-sonographic examinations with histo-pathologic analysis as gold standard.

Mammographic \& US evaluation of the lesions was based on Breast Imaging Reporting and Data System (BIRADS) with classification of these lesions into BIRADS 3, BIRADS 4 and BIRADS 5 categories that were encountered in 6,17 and 8 lesions respectively.

In our study, the age of patients ranged from 21 to 65 years and the largest number of cases was found between 30-40 age group representing 37\% of total cases with mean age group is 42.6 years old with first discovered breast lesions. This matches with the study of Fiki et al., [7] and Liu et al., [8] who found that the largest number of patients with breast diseases that are first discovered was between 30-40 age group and with the similar mean age (42 years old).

As regards the patient's complaint, the most common complaint was painless breast lump in 16 cases (43\%). This matches with Sambasivarao et al., [9] and Sangma et al., [10] who found that painless breast lump is the most common complaint in their studies represented by $(64 \%)$ and $(58.8 \%)$ respectively.

We also found that lesions on the right side represented 15 lesions (48.3\%) and on left side was 12 lesions (38.8\%) and bilateral breast lesions seen in 4 lesions (12.9\%). This matches with study of Sambasivarao et al., [9] who found that about $(57.7 \%)$ of lesions were located on the right side and $(42.5 \%)$ were located on the left side and matches with the study of Sangma et al., [10] who found most of breast lesions on the right side (48\%) and on the left side were (40\%) and bilateral were $(12 \%)$.

As regards, the histo-pathologic analysis of breast lesions revealed 20 benign lesions and 11 malignant lesions. The most common benign lesion was fibroadenoma, which represented 8 lesions (40\%) followed by fibrocystic disease were 3 cases $(15 \%)$, while most common malignant lesion is invasive ductal carcinoma 7 lesions (63.3\%). This matches with study of Sangma et al., [10] they found that with histo-pathologic analysis of breast lesions, fibroadenoma was the most common benign lesion $(50 \%)$ and invasive ductal carcinoma was most common malignant lesion $(60 \%)$ and also with Ş ahin and Aribal, 2013 [11] they reported that and most common benign lesion was fibroadenoma $(43.7 \%)$ and most common malignant lesion was invasive ductal carcinoma (71.4\%).

In our study the Sono-mammographic BIRADS results in association with histo-pathologic results revealed that BIRADS 3 category lesions $(\mathrm{N}=6)$ all of them pathologically proved to be benign lesions (35.3\%), BIRADS 4 category lesions $(\mathrm{N}=$ 17) 14 pathologically proved to be benign lesions 
$(64.7 \%)$ and 3 pathologically proved malignant lesions (27.6\%), BIRADS 5 category lesions $(\mathrm{N}=8)$ all pathologically proved to be 8 malignant lesions $(72.7 \%)$.

Belli et al., [6] classified the detected breast lesions according to their criteria of un-enhanced MRI technique on STIR images and DWI as mass and non-mass lesions. Margins of mass lesion are classified into well circumscribed and noncircumscribed while non-mass lesion is assessed for its distribution as segmental or non-segmental. We classified our 31 breast lesions according to these criteria into mass lesions $(\mathrm{N}=21)$ and nonmass lesion $(\mathrm{N}=10)$, then the margins of mass lesions are further classified into well circumscribed $(\mathrm{N}=11)$ and non-circumscribed which are also classified into irregular or speculated $(\mathrm{N}=10)$. Nonmass lesions are classified into non-mass lesions with segmental distribution ( $\mathrm{N}=5)$, and non-mass lesions with non-segmental distribution $(\mathrm{N}=5)$.

Belli et al., [6] also found that positive predictive value (PPV) of breast lesions according to their criteria of unenhanced MRI technique as margin and signal intensity on STIR images was $98.7 \%$ to $98.8 \%$. This is nearly in accordance with our study that found 8 malignant lesions (80\%) from 10 mass lesions with non-circumscribed margin irregular or speculated.

In the current study the ADC values were automatically calculated by placing the single ROI within lesion with mean diameter $4-10 \mathrm{~mm}^{2}$, the apparent necrotic or cystic components were avoided by referring to conventional MR images, and the fatty glandular breast parenchyma which shows homogenous signal intensity on ADC map was used as a reference. This matches with study of Woodhams et al., [12] as they used the same ROI size and method of application.

In our study the ROC curve showed that the cutoff value of mean ADC to differentiate between benign and malignant lesions was $\leq 1.175 \times 10^{-3}$ $\mathrm{mm}^{2} / \mathrm{s}$ with statistically significant calculated $\mathrm{p}$ value: 0.001 , while the sensitivity, specificity, PPV, NPV and accuracy was $100 \%, 88.2 \%, 84.6 \%, 100 \%$ and $92.86 \%$ respectively at $b$-values $(0,500,1000)$ $\mathrm{s} / \mathrm{mm}^{2}$. This is in accordance with results of Osman and Shebrya, [13] who found that the cut-off value of the mean ADC used to differentiate between the benign and malignant lesions was $1.1 \times 10^{-3} \mathrm{~mm}^{2} / \mathrm{s}$. This is almost similar to the previous studies by Partridge et al., [14] and Yabuuchi et al., [15] who demonstrated slightly higher cut-off value of mean ADC $1.3 \times 10^{-3} \mathrm{~mm}^{2} / \mathrm{s}$ and the minimal difference in ADC threshold can be explained by the difference in many technical variables that affect the ADC value such as different MRI units, pulse sequences, or $b$-values.

Imamura et al., [16] also added that factors related to imaging parameters (magnetic susceptibility, spatial resolution and signal to noise ratio) and those related to the pathophysiologic features (cellular density and tissue component) of the lesions could justify the minimal difference in mean ADC cut off value. In the female body, the hormonal status also affects the water content and reportedly results in a $5.5 \%$ variation in breast ADC throughout the menstrual cycle.

Min et al., [17] stated that lesions with ADC values in the range of $0.89 \pm 0.18 \times 10^{-3} \mathrm{~mm}^{2} / \mathrm{s}$ were called malignant and those between $1.41 \pm 0.56 \mathrm{x}$ $10^{-3} \mathrm{~mm}^{2} / \mathrm{s}$ were called benign. In our study the mean ADC of malignant lesions \pm SD was $0.88 \pm$ $0.17 \mathrm{~mm}^{2} / \mathrm{s}$ and for benign lesions \pm SD was $1.42 \pm$ $0.44 \mathrm{~mm}^{2} / \mathrm{s}$ with statistically significant calculated $p$-value: 0.001 .

We also assessed the diffusion criteria for mass $\&$ non-mass lesions in relation to the histopathologic analysis. The mass lesions $(\mathrm{N}=21) 7$ mass lesions showed restricted diffusion, all pathologically proved to be malignant lesions while 14 mass lesions showed facilitated diffusion all pathologically proved to be benign lesions.

As regards the non-mass lesions $(\mathrm{N}=10) 6$ nonmass benign lesions showed restricted diffusion 4 pathologically proved to be malignant lesions and two pathologically proved to be benign lesions, the remaining 4 non-mass lesions show facilitated diffusion and all proved to be benign lesions. Our results match with studies of Osman and Shebrya, [13] Fiki et al., [7] and Woodhams et al., [12] they stated that most of the malignant lesions show restricted diffusion criteria with some exception detected in some cases of medullary and mucinous carcinoma due to their low cellularity and high water contents. Also most benign lesions show facilitated diffusion with some few exceptions as seen in the intraductal papillomas due to their high cellularity and granulomatous abscesses due to their condensed thick proteinaceous contents.

Also Woodhams et al., [12] found that the complicated cysts with condensed or proteinaceous contents had high signal intensity on DWI even at higher $b$-values denoting restricted diffusion. While the simple cysts show greatly reduced signal intensity on an image obtained at a higher $b$-values denoting facilitated diffusion. This is in accordance 
with our study in which we found that the complicated cyst shows restricted diffusion on DWI with mean ADC value $1.23 \times 10^{-3} \mathrm{~mm}^{2} / \mathrm{s}$, we also found that the simple cyst shows facilitated diffusion on DWI with mean ADC value $2.3 \times 10^{-3} \mathrm{~mm}^{2} / \mathrm{s}$.

Wang et al., [18] added that abscess and mastitis demonstrate high signal intensity on DWI (restricted diffusion) and has low ADC values similar to those of malignant tumours and the area of low ADC value within an abscess usually may show high to intermediate signal intensity on T2-weighted images. So, they considered the clinical data and signs of inflammation are essential in association with radiologic findings in order to achieve the best diagnostic results. This matched with our study about the chronic granulomatous abscess that showed low ADC value of $0.52 \times 10^{-3} \mathrm{~mm}^{2} / \mathrm{s}$.

Arponent et al., [19] reported that $b$-value 1000s/ $\mathrm{mm}^{2}$ was considered optimal for DWI of the breast as the normal mammary gland signals is suppressed and the high signal of malignant lesion is detected. This matches with our results, when using $b$-value $1000 \mathrm{~s} / \mathrm{mm}^{2}$ as the glandular signal from breast parenchyma is suppressed and signal of malignant lesion is easily detected.

We agree with Pereira et al., [20] who stated that using multiple $b$-values it is not necessary as the sensitivity of ADC value with two $b$-values is equal to that with multiple $b$-values and the analysis of an ADC value with two $b$-values may be considered reasonable and acceptable.

We are also in agreement with Woodhams et al., [12] who reported that the optimal $b$-value in cases of fibrocystic disease and cases with dense breast, is $1500 \mathrm{~s} / \mathrm{mm}^{2}$ as the signal of the mammary gland might not be suppressed at $b$-value $=1000$ $\mathrm{s} / \mathrm{mm}^{2}$ and needs higher $b$-value for better evaluation. In our study we had 3 cases of fibroc-ystic disease and 2 cases with dense breast paren-chyma and all of them were evaluated by diffusion weighted imaging using $b$-values of $0,500 \& 1500 \mathrm{~s} / \mathrm{mm}^{2}$.

Bostan et al., [21] also reported that when using low $b$-value the diffusion weighted imaging is affected by water diffusion and by capillary microcirculation which may lead to false high ADC values even with malignant lesions.

In the current study we compared Sono-mammographic BIRADS categories (3,4 and 5) with ADC results (using cut off point of mean ADC $<1$. $175 \times 10^{-3} \mathrm{~mm}^{2} / \mathrm{s}$ ) and referring to the histo-pathologic analysis as standard.
In BIRADS 3 category $(\mathrm{N}=6) 5$ lesions were with mean ADC values above our mean ADC cut off point $1.175 \times 10^{-3} \mathrm{~mm}^{2} / \mathrm{s}$ and all pathologically proved to be benign lesions while one lesion below cut off point of mean ADC $1.175 \times 10^{-3} \mathrm{~mm}^{2} / \mathrm{s}$ proved to be an abscess (its mean ADC was $0.52 \mathrm{x}$ $10^{-3} \mathrm{~mm}^{2} / \mathrm{s}$ ) and we explained before that this may be due to condensed thick proteinaceous contents.

In BIRADS 4 category $(\mathrm{N}=14) 10$ lesions were above our mean ADC cut off point $1.175 \times 10^{-3} \mathrm{~m}$ $\mathrm{m}^{2} / \mathrm{s}$ and all pathologically proved to be benign lesions and 4 lesion below our mean ADC cut off point $1.175 \times 10^{-3} \mathrm{~mm}^{2} / \mathrm{s}$, one lesion proved to be a complicated cyst in a case of fibrocystic disease and 3 lesions proved to be malignant (all were cases of invasive ductal carcinoma).

In BIRADS 5 category $(\mathrm{N}=5)$ all 5 lesion were below our mean ADC cut off point $1.175 \times 10^{-3} \mathrm{~m}$ $\mathrm{m}^{2} / \mathrm{s}$ and all pathologically proved to be malignant lesions.

Elverici et al., [22] have reported that BIRADS 4 category is reserved for findings that do not have the classic appearance of malignancy, but are sufficiently suspicious to justify a recommendation for biopsy with higher risk of malignancy. Lazarus et al., [23] reported that the PPV range from $4 \%$ to $71 \%$. In our study we found that, the overall PPV for malignancy in BIRADS 4 category was (47.8\%) and most lesions categorized under BIRADS 4 category do not have the classic appearance of malignancy.

We agree with Elverici et al., 2015 [22] who reported that the difference in calculation the PPVs of BIRADS 4 category vary over a wide range, probably as a result of differences in the prevalence of breast cancer and the patient selection criteria.

The American college of radiology stated the malignancy probability of BIRADS 5 category lesions is over 95\%, Fu et al., 2011 [24] stated that PPV of BIRADS 5 category was $99.6 \%$. We found that the PPV of BIRADS 5 category was $100 \%$ that slightly close to result of Fu et al., [24] . Other studies reported lower PPV for BIRADS 5 category as they discriminated their lesions as either nonpalpable or palpable.

While as regards BIRADS 3 category Raza et al., [25] stated that the NPV was $99.2 \%$ that in close to our result that found that the NPV of BIRADS 3 was $100 \%$.

Finally, as regards the statistical correlation between sono-mammographic BIRADS results 
with ADC values it revealed that there was weak negative correlation $(r=-4)$ with statistically calculated $p$-value of 0.032 .

This can be explained by the fact that with raising sono-mammographic BIRADS category, the incidence of malignancy is increased. While the higher ADC values are associated with increasing the incidence of the benign lesions and lower ADC values are associated with increasing the incidence of the malignant lesions as there is an inverse correlation between the cellularity of the breast lesions and ADC value, and most of benign lesions show low cellularity and most of malignant lesions show high cellularity. However, some benign lesions may show lower ADC value due to high cellularity as intraductal papilloma and granulomatous or pyogenic abscess due to condensed thick proteinaceous contents, also some malignant lesions show high ADC value due to low cellularity as mucinous and medullary carcinoma.

These results are in agreement with Bostan et al., [21] and Bansal et al., [26] who reported that there was an inverse correlation between the cellularity of the breast lesions and ADC values.

\section{Conclusion:}

Un-enhanced MRI techniques including STIR $\&$ DWI and ADC are useful tools for the detection and characterization of benign and malignant breast lesions especially in patients with contrast intolerance. These techniques showed considerable specificity and positive predictive values in comparison to Sono-mammographic BIRADS and histo-pathologic results.

\section{References}

1- BICKEL H., PINKER K., POLANEC S., MAGOMETSCHNIGG H., WENGERT G., SPICK C. and BALTZER, $P$. Diffusion-weighted imaging of breast lesions: Regionof-interest placement and different ADC parameters influence apparent diffusion coefficient values. European Radiology, 27 (5): 1883-1892, 2017.

2- GIGER M.L., KARSSEMEIJER N. and SCHNABEL J.A.: Breast image analysis for risk assessment, detection, diagnosis, and treatment of cancer. Annual Review of Biomedical Engineering, 15: 3 27-357, 2013.

3- MEISSNITZER T., SEYMER A., KEINRATH P., HOLZMANNHOFER J., PIRICH C., HERGAN K. and MEISSNITZER M.W.: Added value of semi-quantitative breastspecific gamma imaging in the work-up of suspicious breast lesions compared to mammography, ultrasound and 3-T MRI. The British Journal of Radiology, 88 (1051): 20150147, 2015.

4- VIJAYARAGHAVAN G.R., VEDANTHAM S., KHAN A. and KARELLAS A.: Molecular Basis of Breast Cancer Imaging. In Precision Molecular Pathology of Breast Cancer (pp. 1-14). Springer New York, 2015.
5- ZHANG W., JIN G., LIU J., et al.: Diagnostic performance of ADCs in different ROIs for breast lesions. International Journal of Clinical and Experimental Medicine, 8 (8): 12096-12104, 2015.

6- BELLI P., BUFI E., BONATESTA A., et al.: Unenhanced breast magnetic resonance imaging: Detection of breast cancer. European Review for Medical and Pharmacological. Sciences, 20: 4220-4229, 2016.

7- FIKI I., ABDEL-RAHMAN M. and MORSY M.: Assessment of breast mass: Utility of diffusion-weighted MR and MR spectroscopy imaging. The Egyptian Journal of Radiology and Nuclear Medicine, 46: 1327-1335, 2015.

8- LIU S., CONG Y., WANG D., et al.: Breast cancer stem cells transition between epithelial and mesenchymal states reflective of their normal counterparts. Stem. Cell. Reports, 2 (1): 78-91, 2014.

9- SAMBASIVARAO K., ANURADHA B. and SUDH- ARANI B.: Correlation between Sonomammography and Mammography in the Evaluation of Breast Lesions. IOSR Journal of Dental and Medical Sciences (IOSR-JDMS), 1 (15): 13-20, 2016.

10- SANGMA M., PANDA K. and DASIAH S.: A clinicopathological study on benign breast diseases. Journal of Clinical and Diagnostic Research: JCDR, 7 (3): 503, 2013.

11-SAHIN C. and ARIBAL E.: The role of apparent diffusion coefficient values in the differential diagnosis of breast lesions in diffusion-weighted MRI. Diagnostic and Interventional Radiology, 19 (6): 457, 2013.

12- WOODHAMS R., RAMADAN S. and STANWELL P.: Diffusion weighted Imaging of the Breast: Principles and Clinical Applications Radio. Graphics, 31: 1059-1084, 2011.

13- OSMAN M. and SHEBRYA H.: Value of diffusion weighted imaging (DWI) and apparent diffusion coefficient factor (ADC) calculation in differentiation of solid breast lesions. The Egyptian Journal of Radiology and Nuclear Medicine, 47: 363-371, 2016.

14- PARTRIDGE S., DEMARTINI W., KURLAND B., et al.: Differential diagnosis of mammographically and clinically occult breast lesions on diffusion-weighted MRI. Journal of Magnetic Resonance Imaging, 31 (3): 562-570, 2010.

15- YABUUCHI H., MATSUO Y., KAMITANI T., et al.: Non-mass-like enhancement on contrast-enhanced breast MR imaging: Lesion characterization using combination of dynamic contrast-enhanced and diffusion-weighted MR images. European Journal of Radiology, 75 (1): e126e132, 2010.

16- IMAMURA T., ISOMOTO I., SUEYOSHI E., et al.: Diagnostic performance of ADC for Non-mass-like breast lesions on MR imaging. Magnetic Resonance in Medical Sciences, 9 (4): 217-225, 2010).

17- MIN Q., SHAO K., ZHAI L., et al.: Differential diagnosis of benign and malignant breast masses using diffusionweighted magnetic resonance imaging. World Journal of Surgical Oncology, 13 (1): 32, 2015.

18- WANG L., WANG D., FEI X., et al.: A rim-enhanced mass with central cystic changes on MR imaging: How to distinguish breast cancer from inflammatory breast diseases. PloS. One, 9 (3): e90355, 2014. 
19- ARPONENT O., SUDAH M., MASARWAH A., et al.: Diffusion-weighted imaging in 3.0 Tesla breast MRI: Diagnostic performance and tumor characterization using small subregions vs. whole tumor regions of interest. PloS. One, 10 (10): e0138702, 2015

20- PEREIRA F., MARTINS G., DOMINGUES M., et al. Assessment of breast lesions with diffusion-weighted MRI: Comparing the use of different $b$-values. American Journal of Roentgenology, 193 (4): 1030-1035, 2009.

21- BOSTAN T., KOÇ G., SEZGIN G., et al.: Value of Apparent Diffusion Coefficient Values in Differentiating Malignant and Benign Breast Lesions. Balkan Medical Journal, 33 (3): 294-300, 2016.

22- ELVERICI E., BARÇA A., AKTAS H., et al.: Nonpalpable BI-RADS 4 breast lesions: Sonographic findings and pathology correlation. Diagnostic and Interventional Radiology, 21 (3): 189, 2015.
23- LAZARUS E., MAINIERO M., SCHEPPS B., et al.: BIRADS lexicon for US and mammography: Interobserver variability and positive predictive value 1 . Radiology, 239 (2): 385-391, 2006.

24- FU C., HSU H., YU J., et al.: Influence of age on PPV of sonographic BI-RADS categories 3, 4, and 5. Ultraschall in der Medizin-European Journal of Ultrasound, 32 (S 01): 8-13, 2011.

25- RAZA S., CHIKARMANE S., NEILSEN S., et al.: BIRADS 3, 4, and 5 Lesions: Value of US in ManagementFollow-up and Outcome 1. Radiology, 248 (3): 773-781, 2008.

26- BANSAL R., SHAH V. and AGGARWAL B.: Qualitative and quantitative diffusion-weighted imaging of the breast at 3T-A useful adjunct to contrast-enhanced MRI in characterization of breast lesions. The Indian Journal of Radiology \& Imaging, 25 (4): 397-403, 2015.

\title{
دور أنتشار التصوير المرجح فى التفريق بين آفات الثدى الحميلة والخبيثة

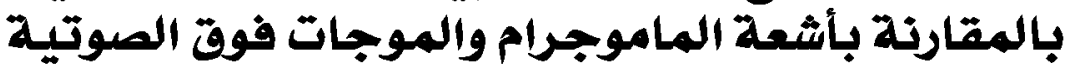

\author{
يعتبر سرطان الثى من أكثر الأمراض أنشاراً ومن أشهر أسباب الوفيات لدى السيدات. \\ تمت هذه الدراسة فى هستشفى المنصورة الجامعى ومركز الأودام فى الفترة ما بين فبراير عا ـr وديسمبر 17.r.
}

وهى قد أشتملت على • ب مريضة يعانون من اب آفة فى الثدى تراوح أعمارهن بين اب و .T سنة وكانت أكثر الإصابات تقع بين

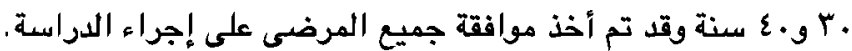

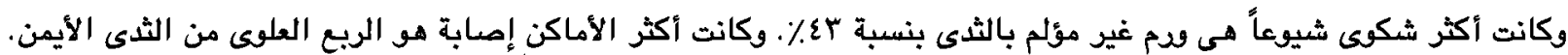

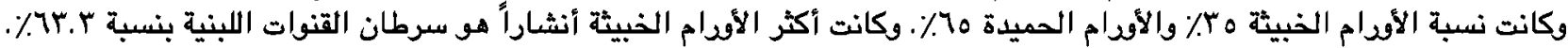

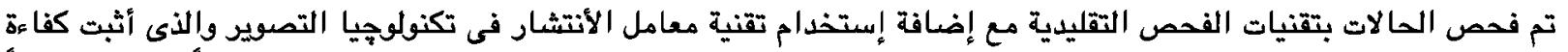

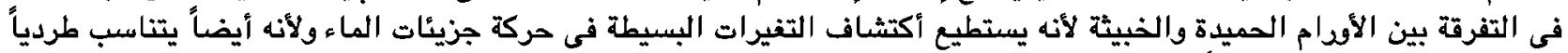

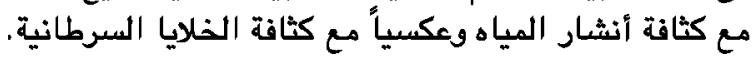

